\title{
Recent Developments in Management of Attention Deficit Hyperactivity Disorder in Children
}

\author{
Rabindran $^{1 *}$, Darshini Madanagopal ${ }^{2}$, Shasidaran $^{3}$
}

${ }^{1}$ Consultant, Neonatologist, Billroth Hospital, Chennai, India

${ }^{2}$ Assistant Professor, Department of Psychology, Institute of Distance Education, University of Madras, Chennai, India

${ }^{2}$ Senior Resident, Department of Radiology, S.R.M. Medical College and Research Centre, Chennai, India

DOI: $10.36347 /$ sjams.2020.v08i09.015

| Received: 06.09.2020 | Accepted: 14.09.2020 | Published: 17.09.2020

*Corresponding author: Rabindran

Abstract

Review Article

Attention Deficit Hyperactivity Disorder (ADHD) is a common neuro-psychiatric disorder. Its symptomatology includes inattention, easy distractibility, hyperactivity, and impulsivity. Ideal approach to ADHD management comprises a combination of pharmacological and behavioral interventions. Pharmacological interventions include use of Stimulants like methylphenidate (MPH), dextroamphetamine or Nonstimulants. Pemoline, Atomoxetine, Clonidine, Guanfacine, Modafinil are other pharmacological agents used in ADHD. Newer drugs include Reboxetine and Venlafaxine. Theophylline and antidepressants like tricyclic antidepressants, desipramine and imipramine are also being tried. Apart from medications, there are many Non-Pharmacological methods which include Behavioural Therapy, Psycho-education, Exercise and Diet therapy. Behavioural interventions consist of techniques like Environmental modification, Parent training intervention, Cognitive Behaviour therapy and Cognitive training. Psycho-education includes Education of parents and family members about ADHD, Group education and direct clinical consultation. Diet management, Exercise, Omega fatty acid and nutritional supplements or Neurofeedback are being tried in the management of ADHD. External Trigeminal Nerve Stimulation (ETNS) is a new medical device to treat children with ADHD. ETNS generates low-level electrical stimulation and sends signals to areas of the brain related to attention, emotion and behaviour. The New Forest Parenting Package (NFPP) is a type of psychosocial intervention in the management of ADHD among children. It combines behavioural intervention with parent- child interaction. Alternative therapy in management of ADHD includes Electroencephalography, Biofeedback Training, Megavitamin Therapy, Herbal Treatments, Body and Craniosacral Manipulation, Sensory Integrative Training and Specific Supplements. Overall the use of integrative treatment model rather a single treatment modality is recommended for management of ADHD.

Keywords: ADHD, Pharmacological Therapy, Interventional Modalities.

Copyright @ 2020: This is an open-access article distributed under the terms of the Creative Commons Attribution license which permits unrestricted use, distribution, and reproduction in any medium for non-commercial use (NonCommercial, or CC-BY-NC) provided the original author and source are credited.

\section{INTRODUCTION}

Attention Deficit Hyperactivity Disorder (ADHD) is now a common neuro-psychiatric disorder. It has an early childhood onset. Broadly speaking ADHD constitutes of 4 major symptomology inattention, easy distractibility, too much activity, and impulsivity. The Diagnostic and Statistical Manual of Mental Disorders (DSM) IV has classified 3 subtypes in ADHD namely predominantly inattentive type, predominantly hyperactive-impulsive type and combined type [1]. However International Statistical Classification of Diseases and Related Health Conditions (ICD) 10 state that presence of both inattention \& hyperactivity - impulsivity are mandatory to make a diagnosis of ADHD.

\begin{abstract}
Management
Various studies over a period of nearly 20 years along with clinical experience have shown that ideal approach to ADHD management comprises a combination of pharmacological and behavioral interventions. Pharmacological interventions include use of Stimulants or Nonstimulants. Behavioral interventions consists of various techniques like Environmental modification, Parent training intervention, Cognitive Behavior therapy and Cognitive training. Apart from these pharmacological and behavioral interventions, sometimes Diet management, Exercise, Omega fatty acid and nutritional supplements or Neurofeedback are being tried in the management of ADHD with various grades of success.
\end{abstract}




\section{Pharmacological Intervention}

Studies have shown that among the medications used in ADHD management, agents that act on dopamine and / or norepinephrine receptors are very effective. There are primarily 2 groups of drugs namely Stimulants and Nonstimulants. Among these Stimulants are the mainstays of treatment [2]. Stimulants with oral preparations like methylphenidate (MPH), dextroamphetamine, and the combination of amphetamine (AMP) and dextroamphetamine, are considered the first-line treatment for ADHD. These drugs act on both dopamine transporter (DAT) and the norepinephrine transporter (NET). They cause presynaptic inhibition of reuptake of catecholamines through stimulation of inhibitory auto-receptors and thereby cause alteration in the functional activity levels of catecholamines.

Amphetamine group of drugs include dextroamphetamine, dextroamphetamine-amphetamine and lisdexamfetamine. Methylphenidates include methylphenidate and dexmethylphenidate. The Stimulant group of drugs for ADHD management are available in short-acting and long-acting forms. A longacting patch of methylphenidate (Daytrana) is available that can be worn on the hip. Advantage of the delayed delivery systems is that they decrease the abuse potential of the stimulant agents.

\section{Pharmacological Classification of ADHD Drugs:}

Drugs used in the management of ADHD can be classified based on the neurotransmitter that they target and based on the primary mechanism of action.

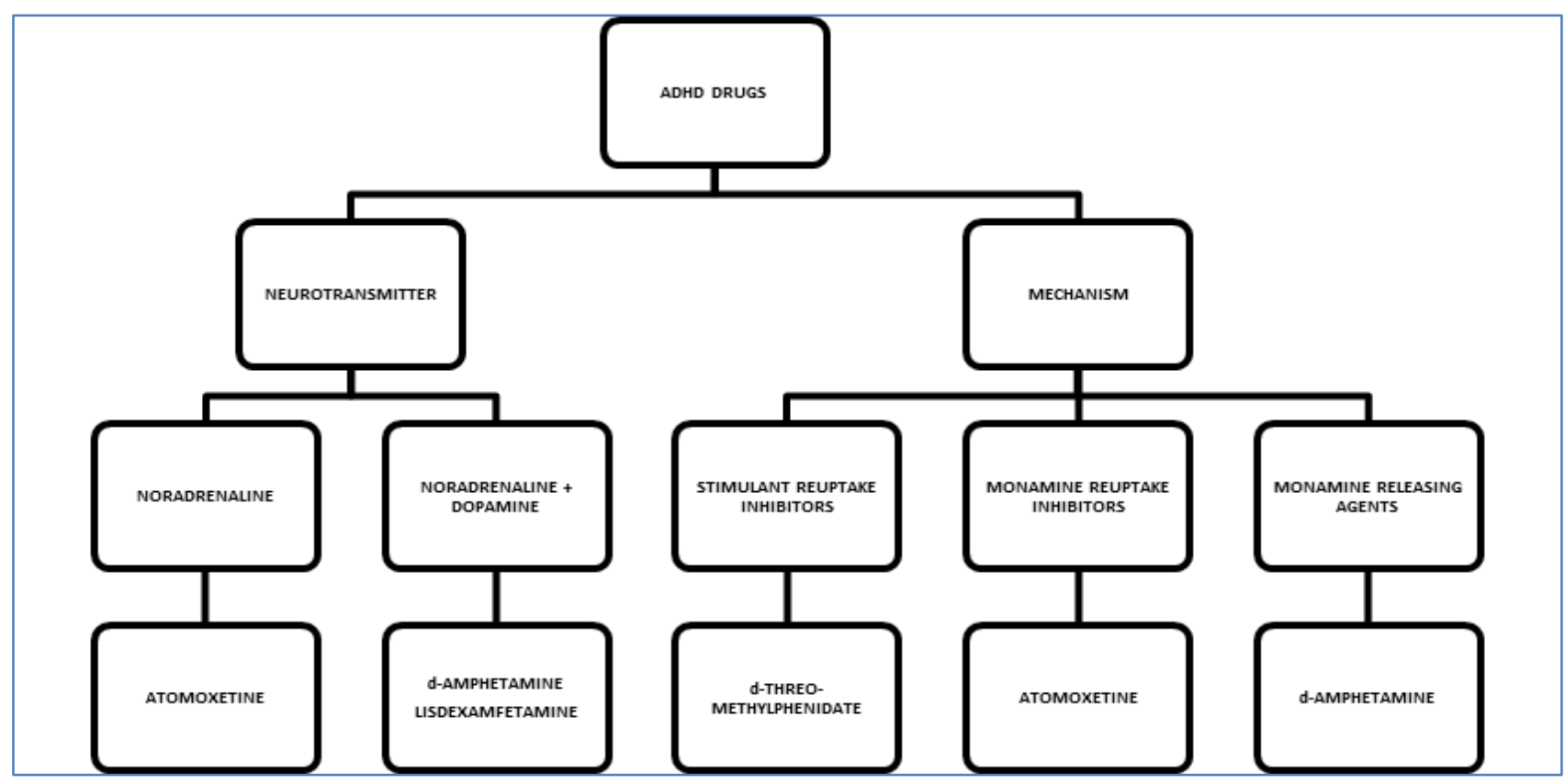

\section{Methylphenidate}

MPH is an approved stimulant drug used in the management of ADHD [3]. Mechanism of action of MPH is by inhibition of reuptake and facilitation of release of norepinephrine and dopamine. Ultimately there is increase in norepinephrine and dopamine levels [4]. The predominant site of action is the dorsolateral prefrontal cortex. It improves attention, concentration, executive function and maintains wakefulness in children with ADHD. It increases dopamine action in basal ganglia. This leads to symptomatic improvement of hyperactivity, which is a part of ADHD.

There are various preparations of MPH like Immediate Release MPH, MPH - Extended Release, MPH-Extended Release Capsules, MPH - Osmotic Release Oral System, MPH - Modified Release, DThreo-MPH- D -MPH and MPH Transdermal Patch. Immediate release MPH has a short half-life of around 2 to 3 hours [5]. It is useful for acute symptomatic relief of ADHD symptoms. However MPH extended release formulation has a half-life of around 12 hours [6]. It provides lasting effect which is approximately equal to twice- or thrice-daily dosing of plain MPH. MPHExtended Release Capsules uses the spheroidal oral drug absorption system. This specific absorption system has a bimodal release profile. Around $50 \%$ of MPH is released initially and rest of the 50\% after 3-5 hours. Thereby symptomatic relief is provided for around 8 hours [7].

MPH - Osmotic Release Oral System uses an osmotic pump process for drug delivery over a 12 hour period [8]. Being a gradual release mechanism there is less chance of adverse reactions or tachyphylaxis. MPH - Modified Release is made up of two types of coated beads consisting of MPH-IR and MPH-ER in a 30:70 ratio [2]. D-Threo-MPH- D -MPH has an equal mixture of D and L-threo MPH. Since it avoids the erythro form of MPH, cardiovascular side effects are minimal [9]. 
MPH Transdermal Patch has the advantage of easy drug delivery in a regular manner throughout the day [10]. There are various patches available in different sizes like $6.25 \mathrm{~cm} 2(0.45 \mathrm{mg} /$ hour $), 12.5 \mathrm{~cm} 2(0.9 \mathrm{mg} /$ hour $)$ and $25 \mathrm{~cm} 2(1.8 \mathrm{mg} /$ hour $)[11]$.

\section{Amphetamine}

Amphetamine (AMP) is a commonly used drug in the management of ADHD. Nowadays combination of both immediate and extended release preparations of Mixed Amphetamine Salts (MAS) are being studied. These preparations have equal proportions of D-amphetamine saccharate, D,1amphetamine asparate, D-amphetamine sulfate and D, 1amphetamine sulfate. Since the 2 isomers have different properties, it is beneficial as some children have a tendency to respond better to one isomer than the other [6].

MAS - Extended Release have a 50:50 ratio of immediate release and delayed release beads [12]. The immediate release beads release MAS immediately whereas delayed release beads release it 4 to 6 hours after the dosing. Thereby there is acute symptom relief as well as long standing benefit from such preparations. Lisdexamphetamine dimesylate is an Amphetamine prodrug. It is inactive in this form. It gets metabolised to the active form dextroamphetamine due to the action of a peptidase enzyme. Hence this prodrug has the ability to provide a longer duration of effect that lasts over a whole day [3]. Another advanatage is that the prodrug attenuates the onset and intensity of AMP like effects. It is less reinforcing and has lower abuse potential.

\section{Pemoline}

Pemoline is a central nervous system stimulant drug [13]. It has been used in ADHD. It has a structure which is different from MPH and AMP. Mechanism of action of Pemoline is by increasing central dopaminergic transmission and thereby relieving symptoms of ADHD.

\section{Atomoxetine}

Atomoxetine is the only non-stimulant medication approved by the FDA for the treatment of ADHD in children [14]. Mechanism of action of Atomoxetine is through inhibition of the presynaptic norepinephrine transporter. It improves ADHD symptoms by improving efficiency in the norepinephrine system.

\section{Clonidine and Guanfacine}

Alpha-adrenergic agonists are group of drugs which are being used as an alternative in children who don't respond to stimulant drugs [15]. Clonidine and Guanfacine are Alpha-adrenergic agonists currently being used in the management of ADHD. It has been proven that guanfacine extended release can be administered with MPH or amphetamine safely and that it results in good clinical results [16]. A-Adrenergic agonists and stimulants have different neurotransmitter systems and combination of these 2 drugs has a complementary mechanism. Both act together and modulate prefrontal cortex function. Guanfacine affects norepinephrine discharge rates in the locus ceruleus, and this indirectly affects dopamine firing rates.

\section{Bupropion}

Bupropion has been used in certain cases of ADHD [17]. Among adolescents, it has been found to be particularly useful in managing symptoms of ADHD coupled with nicotine dependence because of its primary effect on smoking cessation.

\section{Modafinil}

Modafinil is a new stimulant drug which is distinct from AMP [18]. It has been FDA approved for the treatment of narcolepsy. Mechanism of action of Modafinil is by activation of specific hypothalamic regions. It is being studied in the management of ADHD. It is a wake promoting agent. It selectively activates the cortex without generalized effects on the central nervous system.

\section{Other Drugs with Anecdotal Evidence}

There are various studies nowadays regarding the newer drugs in management of ADHD among children. Reboxetine [19] and Venlafaxine [20] are selective norepinephrine reuptake inhibitors, which have been found beneficial in the management of ADHD. Selegiline is an irreversible type B monoamine oxidase inhibitor that is metabolised into amphetamine and methamphetamine [21]. Recently medications used in Alzheimer's disease have been tried to enhance cognition in children with ADHD. Theophylline is a popular bronchodilator. Its mechanism of action is adenosine receptor antagonism which may have an effect on central dopaminergic and noradrenergic neurotransmission. This probably helps in ADHD [22].

Studies have shown positive results with agents like polyunsaturated fatty acids, acetyl-Lcarnitine and iron supplements [23]. MPH and AMP have cognition enhancing effects by indirect stimulation of alpha-2 adrenoceptors and D-1 dopamine receptors in the Pre Frontal Cortex. Second-line agents for similar effects include antidepressants like tricyclic antidepressants, desipramine, imipramine and venlafaxine [24].

\section{Non-pharmacological Therapies for ADHD}

Apart from medications, there are many NonPharmacological methods in the management of ADHD. These include Behavioral Therapy, Psychoeducation, Exercise and Diet therapy [25]. Behavioural therapy includes Cognitive Behavioural therapy directed towards parents, Parent-led and Classroom-led Behavioural intervantions and Neurofeedback. Psychoeducation includes Education of parents and family 
members about ADHD, Group education [26] and direct clinical consultation. Parent Training for management is universally applicable for all school age and preschool children [27]. Classroom interventions can be beneficial in school age children [28]. Social skills training and cognitive behavioural therapy are useful for adolescents with ADHD [29].

\section{Interventional Modalities for ADHD}

The 2 major intervention modalities in the management of ADHD in children include Behavioural Intervention and Educational Intervention. These interventions improve self-observation skills and coping skills, which are compromised by their ADHD.

\section{Behavioural Intervention}

Behavioural Intervention has been tried as a primary modality of ADHD treatment for children between 4-6 years of age [30]. It is considered as a complimentary treatment modality in older children and adolescents. Behavioral Intervention improves academic performance, social skills, defiant and aggressive behavior in children with ADHD. There are various components in Behavioural Intervention which include Positive reinforcement, Time-out, Response cost and Token economy [31].

\section{Educational Intervention}

Educational Intervention is primarily used for management of ADHD in children more than 5 years of age. In this method of Educational Intervention there are various modifications in the classroom which include Using Board for writing assignments, Making child with ADHD to Sit near the teacher, Providing extra time to complete tasks, Allowing to write tests in an environment with less distraction, Assigning a Study Buddy or a Shadow Teacher [32].

\section{Psychosocial Intervention}

Among psychosocial interventions, parent behavior management training is popular. It has been shown beneficial in management of children with ADHD. It involves training parents to implement home behaviour therapy programs, to target both home and school behaviour, generally using contingency management approaches. Parents are oriented towards concept of positive reinforcement, usage of functional behaviour analysis to negative behaviors, and tracking specific behaviours. Behavioural targets are set and reinforcers are planned. Cognitive behavioural therapy primarily concentrates on problem solving. Social skills training are a type of cognitive behavioural intervention which targets social skills directly [33]. It has been found useful in management of ADHD among adolescents.

\section{External Trigeminal Nerve Stimulation (ETNS) System}

External Trigeminal Nerve Stimulation (ETNS) is a new medical device to treat children with
ADHD. It has been appoved by FDA for use in children between 7 to 12 years of age. ETNS is a small device roughly about the size of a cell phone. It can be used at home under parental supervision, when the child is sleeping. ETNS generates low-level electrical stimulation which is carried through a wire to a small patch placed on the child's forehead. It sends signals to areas of the brain related to attention, emotion and behavior. It is being studied for symptomatic management of children with ADHD who are not on any medications.

\section{New Forest Parenting Package (NFPP)}

The New Forest Parenting Package (NFPP) is a type of psychosocial intervention in the management of ADHD among children. The main basis of NFPP is the pivotal role of constructive and reciprocal parent child interactions in the psychological development of attention and impulse control among preschool age children. It combines behavioural intervention with parent -child interaction. It targets parent- child processes involved in mediating development of attention and self-organizing skills. Parents are taught to be supportive, aware of the child's developmental level, and set appropriate and challenging goals [34].

Prominent treatment goals in NFPP include reducing negative reactions of parents, promoting authoritative parenting technique with setting limits appropriately, increasing positive and constructive interaction between the parent and the child, providing tailored motivation and scaffolding of attention and self-organizational competencies.

\section{Alternative Therapy}

Apart from the pharmacological and nonpharmacological intervention therapies for management of children with ADHD, there are also other approaches which are being studied. These include Electroencephalography, Biofeedback Training, Megavitamin Therapy, Herbal Treatments, Body and Craniosacral Manipulation, Sensory Integrative Training and specific Supplements [35]. Overall the use of integrative treatment model rather a single treatment modality is recommended for management of ADHD.

\section{CONCLUSION}

With the advancement of scientific diagnostic and therapeutic, etiology and management of various diseases and disorders are changing. In management of ADHD among children along with traditional treatment practices, there are novel therapeutic approaches and combination interactive therapies which are being studied. The availability of extended release, delayed release, prodrug, and transdermal stimulant formulations, as well as alternative non-stimulant agents, opens newer dimensions in the management of ADHD among children. 


\section{REFERENCE}

1. American Psychiatric Association. Diagnostic and statistical manual of mental disorders (DSM-5®). American Psychiatric Pub; 2013 May 22.

2. Faraone SV, Buitelaar J. Comparing the efficacy of stimulants for ADHD in children and adolescents using meta-analysis. European child \& adolescent psychiatry. 2010 Apr 1;19(4):353-64.

3. Findling RL. Evolution of the treatment of attention-deficit/hyperactivity disorder in children: a review. Clinical therapeutics. 2008 May 1;30(5):942-57.

4. Volkow ND, Fowler JS, Wang G, Ding Y, Gatley SJ. Mechanism of action of methylphenidate: insights from PET imaging studies. Journal of attention disorders. 2002 Apr;6(1_suppl):31-43.

5. Atzori P, Usala T, Carucci S, Danjou F, Zuddas A. Predictive factors for persistent use and compliance of immediate-release methylphenidate: a 36-month naturalistic study. Journal of child and adolescent psychopharmacology. 2009 Dec 1;19(6):673-81.

6. De Sousa A, Kalra G. Drug therapy of attention deficit hyperactivity disorder: Current trends. Mens sana monographs. 2012 Jan;10(1):45.

7. Biederman J, Quinn D, Weiss M, Markabi S, Weidenman M, Edson K, Karlsson G, Pohlmann H, Wigal S. Efficacy and safety of Ritalin ${ }^{\circledR}$ LA $^{\mathrm{TM}}$, a new, once daily, extended-release dosage form of methylphenidate, in children with attention deficit hyperactivity disorder. Pediatric Drugs. 2003 Dec 1;5(12):833-41.

8. Kim Y, Shin MS, Kim JW, Yoo HJ, Cho SC, Kim BN. Neurocognitive effects of switching from methylphenidate-IR to OROS-methylphenidate in children with ADHD. Human Psychopharmacology: Clinical and Experimental. 2009 Mar;24(2):95-102.

9. Ding YS, Gatley SJ, Thanos PK, Shea C, Garza V, Xu Y, Carter P, King P, Warner D, Taintor NB, Park DJ. Brain kinetics of methylphenidate (Ritalin) enantiomers after oral administration. Synapse. 2004 Sep 1;53(3):168-75.

10. Faraone SV, Glatt SJ, Bukstein OG, Lopez FA, Arnold LE, Findling RL. Effects of once-daily oral and transdermal methylphenidate on sleep behavior of children with ADHD. Journal of Attention Disorders. 2009 Jan;12(4):308-15.

11. Pelham Jr WE, Manos MJ, Ezzell CE, Tresco KE, Gnagy EM, Hoffman MT, Onyango AN, Fabiano GA, Lopez-Williams A, Wymbs BT, Caserta D. A dose-ranging study of a methylphenidate transdermal system in children with ADHD. Journal of the American Academy of Child \& Adolescent Psychiatry. 2005 Jun 1;44(6):522-9.

12. Mcgough JJ, Biederman J, Wigal SB, Lopez FA, Mccracken JT, Spencer T, Zhang Y, Tulloch SJ. Long-term tolerability and effectiveness of oncedaily mixed amphetamine salts (Adderall XR) in children with ADHD. Journal of the American
Academy of Child \& Adolescent Psychiatry. 2005 Jun 1;44(6):530-8.

13. Safer DJ, Zito JM, Gardner JF. Pemoline hepatotoxicity and postmarketing surveillance. Journal of the American Academy of Child \& Adolescent Psychiatry. 2001 Jun 1;40(6):622-9.

14. Hazell PL, Kohn MR, Dickson R, Walton RJ, Granger RE, van Wyk GW. Core ADHD symptom improvement with atomoxetine versus methylphenidate: a direct comparison metaanalysis. Journal of Attention Disorders. 2011 Nov;15(8):674-83.

15. May DE, Kratochvil CJ. Attention-deficit hyperactivity disorder. Drugs. 2010 Jan 1;70(1):1540.

16. Sallee FR, Mcgough J, Wigal T, Donahue J, Lyne A, Biederman J, SPD503 Study Group. Guanfacine extended release in children and adolescents with attention-deficit/hyperactivity disorder: a placebocontrolled trial. Journal of the American Academy of Child \& Adolescent Psychiatry. 2009 Feb $1 ; 48(2): 155-65$

17. Faraone SV. Using meta-analysis to compare the efficacy of medications for attentiondeficit/hyperactivity disorder in youths. Pharmacy and Therapeutics. 2009 Dec;34(12):678.

18. Kahbazi M, Ghoreishi A, Rahiminejad F, Mohammadi MR, Kamalipour A, Akhondzadeh S. A randomized, double-blind and placebo-controlled trial of modafinil in children and adolescents with attention deficit and hyperactivity disorder. Psychiatry research. 2009 Aug 15;168(3):234-7.

19. Arabgol F, Panaghi L, Hebrani P. Reboxetine versus methylphenidate in treatment of children and adolescents with attention deficit-hyperactivity disorder. European child \& adolescent psychiatry. 2009 Jan 1;18(1):53-9.

20. Ratner S, Laor N, Bronstein Y, Weizman A, Toren P. Six-week open-label reboxetine treatment in children and adolescents with attentiondeficit/hyperactivity disorder. Journal of the American Academy of Child \& Adolescent Psychiatry. 2005 May 1;44(5):428-33.

21. Mohammadi MR, Ghanizadeh A, Alaghband-Rad J, Tehranidoost M, Mesgarpour B, Soori H. Selegiline in comparison with methylphenidate in attention deficit hyperactivity disorder children and adolescents in a double-blind, randomized clinical trial. Journal of Child \& Adolescent Psychopharmacology. 2004 Sep 1;14(3):418-25.

22. Mohammadi MR, Kashani L, Akhondzadeh S, Izadian ES, Ohadinia S. Efficacy of theophylline compared to methylphenidate for the treatment of attention-deficit hyperactivity disorder in children and adolescents: a pilot double-blind randomized trial. Journal of clinical pharmacy and therapeutics. 2004 Apr;29(2):139-44.

23. Dopheide JA, Pliszka SR. Attention-deficithyperactivity disorder: an update. Pharmacotherapy: The Journal of Human 
Pharmacology and Drug Therapy. 2009 Jun;29(6):656-79.

24. Spencer T, Biederman J, Wilens T, Harding M, O'DONNELL DE, Griffin S. Pharmacotherapy of attention-deficit hyperactivity disorder across the life cycle. Journal of the American Academy of Child \& Adolescent Psychiatry. 1996 Apr 1;35(4):409-32.

25. Sonuga-Barke EJ, Brandeis D, Cortese S, Daley D, Ferrin M, Holtmann M, Stevenson J, Danckaerts M, Van der Oord S, Döpfner M, Dittmann RW. Nonpharmacological interventions for ADHD: systematic review and meta-analyses of randomized controlled trials of dietary and psychological treatments. American Journal of Psychiatry. 2013 Mar;170(3):275-89.

26. Sonuga-Barke EJ, Daley D, Thompson M, LaverBradbury C, Weeks A. Parent-based therapies for preschool attention-deficit/hyperactivity disorder: a randomized, controlled trial with a community sample. Journal of the American Academy of Child \& Adolescent Psychiatry. 2001 Apr 1;40(4):402-8.

27. Lee PC, Niew WI, Yang HJ, Chen VC, Lin KC. A meta-analysis of behavioral parent training for children with attention deficit hyperactivity disorder. Research in developmental disabilities. 2012 Nov 1;33(6):2040-9.

28. Pelham Jr WE, Fabiano GA. Evidence-based psychosocial treatments for attentiondeficit/hyperactivity disorder. Journal of Clinical Child \& Adolescent Psychology. 2008 Mar 3;37(1):184-214.

29. Fehlings DL, Roberts W, Humphries T, Dawe G. Attention deficit hyperactivity disorder: does cognitive behavioral therapy improve home behavior?. Journal of Developmental and Behavioral Pediatrics. 1991 Aug.

30. Subcommittee on Attention-Deficit/Hyperactivity Disorder, Steering Committee on Quality Improvement and Management. ADHD: clinical practice guideline for the diagnosis, evaluation, and treatment of attention-deficit/hyperactivity disorder in children and adolescents.

31. Floet AL, Scheiner C, Grossman L. Attentiondeficit/hyperactivity disorder. Paediatr Rev. 2010;31:56-69.

32. Dalwai S, Unni J, Kalra V, Singhi P, Shrivastava L, Nair M. Consensus statement of the Indian Academy of Pediatrics on evaluation and management of Attention Deficit Hyperactivity Disorder. Indian Pediatrics. 2017 Jun 1;54(6):4818.

33. Klingberg T, Fernell E, Olesen PJ, Johnson M, Gustafsson P, Dahlström K, Gillberg CG, Forssberg H, Westerberg H. Computerized training of working memory in children with ADHD-a randomized, controlled trial. Journal of the American Academy of child \& adolescent psychiatry. 2005 Feb 1;44(2):177-86.

34. Sonuga-Barke EJ, Thompson M, Abikoff H, Klein $\mathrm{R}$, Brotman LM. Nonpharmacological interventions for preschoolers with ADHD: the case for specialized parent training. Infants \& Young Children. 2006 Apr 1;19(2):142-53.

35. Arnold LE. Alternative treatments for adults with attention-deficit hyperactivity disorder (ADHD). Annals of the New York Academy of Sciences. 2001 Jun;931(1):310-41. 